\title{
Burden of Dyspepsia in Rural and Urban Asia: Author's Reply
}

TO THE EDITOR: We sincerely appreciate the interest and comments of $\mathrm{Dr} . \mathrm{Lu}^{1}$ on our recently published paper in this journal. ${ }^{2}$ Dr. Lu points out that the differences in economic impact of dyspepsia between rural and urban communities were not entirely surprising, due to differences in socioeconomic status and healthcare facilities between both populations. Whilst we agree with this statement, it is important to highlight that no such observation has been published in the English literature to date. In the light that dyspepsia is a condition that affects communities in both rural and urban areas in Asia, our findings are highly relevant. This difference in economic impact additionally provides useful information for health economists and providers, particularly in developing strategies on where to focus healthcare services. It is true that studying the economic impact between subjects with and without dyspepsia, regardless of type of community, would have provided further information on the economic impact of dyspepsia. However, the questionnaire that we had developed for the population-based study was not designed to obtain this data. Nevertheless, we hope that this important aspect can be examined in future studies in this area.

We also concur with Dr. Lu's second statement that histamine 2 blocker or proton pump inhibitor therapy have both been shown to be superior to simple antacids in the initial management of uninvestigated dyspepsia. ${ }^{3}$ We believe there are at least 2 possibilities for the excessive use of antacids as opposed to anti-secretory therapy in our population. Firstly, a significant number of adults with dyspepsia were self-medicating, and antacids are more available in both pharmacies and retail outlets in this country compared to anti-secretory medication. Whilst the cost of some generic histamine 2 blockers are relatively low, the retail outlet price of antacids remains the cheapest for the average consumer in this country. Secondly, most patients consulted primary care physicians and not secondary care specialists. It is possible that the primary care physicians in this country are less familiar with evidence-based management of dyspepsia compared to Gastroenterologists or Internal Physicians, resulting in a greater use of antacids compared to anti-secretory therapy. Although the latter is only an assumption, it is likely that more local or regional guidelines, such as the recently published Asian Consensus on Functional Dyspepsia, ${ }^{4}$ will prove useful in disseminating evidence for clinicians locally.

Sanjiv Mahadeva and Khean-Lee Goh Division of Gastroenterology, Department of Medicine Faculty of Medicine, University of Malaya Kuala Lumpur, Malaysia

1. Lu CL. Burden of dyspepsia in rural and urban Asia. J Neurogastroenterol Motil 2012;18:229.

2. Mahadeva S, Yadav H, Everett SM, Goh LK. Economic impact of dyspepsia in rural and urban Malaysia: a population-based study. J Neurogastroenterol Motil 2012;18:43-57.

3. Moayyedi P, Soo S, Deeks J, Delaney B, Innes M, Forman D. Pharmacological interventions for non-ulcer dyspepsia. Cochrane Database Syst Rev 2006;(4):CD001960.

4. Miwa H, Ghoshal UC, Fock KM, et al. Asian consensus report on functional dyspepsia. J Gastroenterol Hepatol Published Online First: 6 Dec 2011. doi: 10.1111/j.1440-1746.2011.07037.x

\section{Conflicts of interest: None.}

